\title{
End-of-life issues in genetic disorders: Literature and research directions
}

Ann R. Knebel, RN, DNSc, FAAN, and Carole Hudgings, PhD, RN, FAAN

\begin{abstract}
Part I of this report summarizes findings from a literature search on end of life in people with genetic disorders. There is a paucity of research on this topic; thus this article includes descriptive studies, clinical reviews, and case presentations. Part II describes the proceedings of a workshop to discuss end-of-life issues in people with genetic disorders. The workshop brought together clinicians, researchers, and people living with genetic disorders to discuss this topic. The purpose of this article is to summarize the literature and workshop proceedings to provide directions for future investigation in this important area. Genet Med 2002:4(5):366-372.
\end{abstract}

Key Words: death, dying, inheritance, end of life, genetic disorders

There is currently very little research detailing issues that are faced at the end of life for people with genetic disorders, and there is a lack of a good model of care to follow for end-of-life treatment or withdrawal of treatment. The articles reviewed for the present report include primarily case reports and descriptive studies. Some of the issues addressed in the papers include but are not limited to the following: psychological and bereavement issues ${ }^{1-4}$; cost of care at the end of life ${ }^{5,6}$; decision-making regarding use of technological interventions ${ }^{5-8}$; psychosocial reactions of parents and siblings ${ }^{1,7,9}$; availability of supportive services ${ }^{2}$; coordination-of-care concerns ${ }^{2}$; advance directives ${ }^{2,5,6}$; effect of death on siblings ${ }^{1,2,4,7}$; quality of life $^{2,5,10,11}$; ethics ${ }^{8,12}$; and palliative care. , $^{2,11,13,14}$

Each of the papers included in this review approaches the issue from a unique, but often limited perspective such as a medical and cultural perspective of starting mechanical ventilation for Werdnig-Hoffmann disease patients in Japan ${ }^{8}$ or costs and availability of palliative care in Australia. ${ }^{2}$ While the current literature on end-of-life issues in genetic disorders is limited in scope, it provides a starting point from which to learn about the issues surrounding end of life in genetic disorders. The uniqueness of end-of-life issues in genetic disorders is addressed more specifically in the summary of the workshop described in Part II.

\section{METHODS}

This review covers 14 papers published in medical, psychological, and nursing journals from July 1988 to February 2001. Searches were conducted using PubMed indexed for MED-

From the National Institute of Nursing Research at the National Institutes of Health, Bethesda, MD.

Ann R. Knebel, RN, DNSc, FAAN, 31 Center Drive, MSC 2178, Building 31, Room 5B10, Bethesda, MD 20892-2178.

Received: April 4, 2002.

Accepted: June 7, 2002.

DOI: 10.1097/01.GIM.0000029039.86752.02
LINE, Psychological Reports, nursing journals, APA/PsycINFO, and Dissertation Abstracts International, at the National Library of Medicine, National Institutes of Health, in Bethesda, Maryland. Searches were done with the key words "end-of-life issues in people with genetic illnesses." Thirty-two papers were identified in the search. Only 14 of those 32 papers actually deal with the topic of interest (see Table 1). The others concern diseases that are not genetically transmitted or simply describe medical treatment of the condition or an approach to care that does not include a discussion of end-of-life issues. This review focuses on the genetic disorders described in Table 2 , and the articles will be organized into the following four categories:

- Palliative care

- Use of technological interventions

- Ethical decisions

- Issues facing caregivers and the community

\section{PALliative CARE}

The definition of palliative or comfort care is changing. In the past, palliative care was thought to be important only in the terminally ill, typically during the last 6 months of life. Today palliative care encompasses physical, psychological, emotional, and spiritual support for the individual and family from the time of diagnosis of a life-limiting illness through bereavement care following the death. Most models of palliative care are based on treatment of terminally ill cancer patients, who are usually adults. Therefore, developed palliative care models for children are lacking.

In researching the potential role of palliative care services for individuals with Duchenne or Becker muscular dystrophy or spinal muscular atrophy, Parker and colleagues ${ }^{2}$ interviewed 13 South Australian families with a child who had either died over the previous 7-year period or were actively caring for an individual with one of these diseases. The participants were asked questions regarding the experience of caring (formal and 
Table 1

Summary of articles

\begin{tabular}{llll}
\hline Authors & \multicolumn{1}{c}{ Population } & Sample size & Research desig \\
\hline Mack \& Berman $^{1}$ & $\begin{array}{c}\text { Tay-Sachs and related } \\
\text { disorders }\end{array}$ & Program analys \\
Parker et al. $^{2}$ & $\begin{array}{c}\text { Muscular dystrophy and } \\
\text { spinal muscular atrophy }\end{array}$ & 13 families & $\begin{array}{c}\text { Qualitative } \\
\text { interviews }\end{array}$
\end{tabular}

Ramer-Chrastek ${ }^{3} \quad$ Adrenal leukodystrophy

Wolfe ${ }^{4}$

Hilton et al. ${ }^{5}$

Zellweger syndrome

Duchenne muscular dystrophy

Tonelli 6

Cystic fibrosis

Livneh et al. ${ }^{7} \quad$ Progeria

Sakakihara et al. ${ }^{8} \quad$ Werdnig-Hoffmann

33 pediatricians Survey

Labbe $^{9}$

Batten disease

32 caregivers

Christian et al. ${ }^{10} \quad$ Cystic fibrosis

Ferrin et al. ${ }^{11}$

Cystic fibrosis

Werdnig-Hoffman

$\operatorname{Dagi}^{12}$

Mitchell et al. ${ }^{13} \quad$ Cystic fibrosis

45

Robinson et al. ${ }^{14} \quad$ Cystic fibrosis
Comparative

Case report

Physician survey

Case study

Case reports

Review of literature and description of clinical program

Review of literature

Review of literature

Case study

Case study

Phyician survey

Retrospective
Key findings

Describes the process of forming a long-term, open-ended group to allow parents of children with Tay-Sachs and related disorders to work together on mutual concerns.

Families identified issues important in the care of children with these diseases in Australia. Themes included lack of coordination of services and access to care, lack of support for siblings, inadequate bereavement care and limited discussion of option of ventilatory support and advance directives. Terminal care for individuals with these genetic disorders needs improvement.

Describes how school staff worked together with a hospice team to help a dying child remain involved with his class when he was still able to attend school and then as he declined at home. Support for the students continued after the death of their classmate.

Describes the role of hospice in working with two families who were facing the death of a second child due to this genetic disorder.

Technological advances have added complexity to medical decision-making for patients with DMD. Patients and families who have been adequately informed about technologies most often choose to use them. Many patients with DMD do well on long-term ventilation, but some find their quality of life is less than desirable and choose to discontinue this method of life prolongation.

Despite recent advances in the treatment of patients with CF, most of those with the disease continue to die before their 30th birthday. Care at the end of life for patients with CF seems to be a mix of preventive, therapeutic, and palliative treatments. Recognition of the importance of end-of-life care does not take away from the focus on ameliorating symptoms and, ultimately, finding a cure but rather acknowledges that delivery of optimal care does not end when death is imminent.

Although a great deal of clinical data exists on the psychosocial adaptation processes of parents who face the death of their children, no studies were found in which clinical data were obtained directly from the families of dying children. Such studies are needed. Despite the lack of research, psychosocial intervention guidelines are offered.

In Japan, families strongly endorse use of mechanical ventilation in children with this fatal disorder. $80 \%$ of pediatricians thought the quality of life of the ventilatordependent patients was not adequate, but $50 \%$ stated they would start ventilator assistance if they had a new patient with Werdnig-Hoffman. The secure national insurance program and general pro-life beliefs could affect physicians' decision to use life-sustaining treatments in patients with this disease.

Caregivers of children with Batten disease were more depressed and anxious than caregivers of children with less severe medical illnesses. The caregivers of children with Batten disease also reported less family cohesiveness and more negative effects on their schedule and health. The caregivers of children with terminal genetic illnesses may be at greater risk for emotional and family difficulties, and psychological interventions might be helpful.

In-depth analysis of the events surrounding an adolescent's decision to undergo lung transplantation highlights the need to provide psychosocial support as soon as the course of CF turns downward and lung transplantation is considered. The importance of quality of life was highlighted.

Palliative care is essential to the care of patients with chronic, life-threatening, and life-limiting illnesses, and it should become the dominant mode of care when curative interventions are ineffective and relief of physical or psychological suffering becomes the focus of care.

Ethical issues arise in neonates with Werdnig-Hoffman when decisions about removal of life support are considered. Three principles are outlined: (1) While pain and suffering are difficult to assess in the neonate, this difficulty should not influence the judgments that are made about pain and suffering. (2) Limitations of ethical theory in critical care are not really limitations and do not justify use of intuition for decision-making. (3) The needs and desires of the health care professionals with regard to removal of life support are legitimately constrained by their professional status.

Respiratory disease remains the most common cause of death in patients with CF. Lung transplantation is frequently considered, but most patients die without having a transplant. Discussions on end-of-life care could be considered sooner.

The majority of patients with CF at one institution continued to receive intravenous antibiotics and/or oral vitamins while being treated with opiates for terminal pain and dyspnea. The model of comfort care developed in childhood cancer does not adequately describe the combination of preventive, therapeutic, and palliative care given at the end of life at this institution. 
Table 2

Genetic disorders included in review

\begin{tabular}{|c|c|c|c|c|}
\hline Disease & $\begin{array}{l}\text { Typical age } \\
\text { of onset }\end{array}$ & $\begin{array}{l}\text { Typical life } \\
\text { expectancy }\end{array}$ & $\begin{array}{l}\text { Typical cause } \\
\text { of death }\end{array}$ & $\begin{array}{c}\text { OMIM } \\
\text { no. }\end{array}$ \\
\hline Cystic fibrosis & First year, but may be later & $50 \%>30 \mathrm{yr}$ & Pulmonary complications & 219700 \\
\hline Adrenoleukodystrophy & $\begin{array}{l}\text { Different variants: neonatal, } \\
\text { childhood, later onset }\end{array}$ & $\begin{array}{l}\text { Depends on } \\
\text { variant }\end{array}$ & $\begin{array}{l}\text { Neurological symptoms; } \\
\text { vegetative state for years }\end{array}$ & 300100 \\
\hline $\begin{array}{l}\text { Zellweger syndrome (aka cerebrohepatorenal } \\
\text { syndrome) }\end{array}$ & Prenatal & Most $<1$ yr & Multiorgan failure & 214100 \\
\hline Tay-Sachs & $3-6$ months of age & Usually by age 3 & Neurological deterioration & 272750 \\
\hline $\begin{array}{l}\text { Progeria (aka Hutchinson-Gilford } \\
\text { syndrome) }\end{array}$ & First year of life & Early teens & $\begin{array}{l}\text { Cardiovascular-related or } \\
\text { stroke due to progressive } \\
\text { atherosclerosis }\end{array}$ & 176670 \\
\hline $\begin{array}{l}\text { Batten disease (aka amaurotic familial idiocy } \\
\text { or cerebral sphingolipidosis) }\end{array}$ & $\begin{array}{l}\text { After age } 2 \text {, teens, or as an } \\
\text { adult }\end{array}$ & Indefinite & $\begin{array}{l}\text { Muscle incoordination, } \\
\text { blindness, mental } \\
\text { deterioration, seizures }\end{array}$ & 256540 \\
\hline $\begin{array}{l}\text { Duchenne muscular dystrophy (aka } \\
\text { pseudohypertrophic muscular dystrophy) }\end{array}$ & In males $1-6$ years old & By age 15 & Cardiopulmonary disorders & 310200 \\
\hline Becker muscular dystrophy & $20 s-30 s$ & $\begin{array}{l}\text { Relatively } \\
\text { advanced age }\end{array}$ & Cardiopulmonary disorders & 300376 \\
\hline $\begin{array}{l}\text { Werdnig-Hoffmann (aka spinal muscular } \\
\text { atrophy) }\end{array}$ & Birth & By age 3 & Pneumonia & 253300 \\
\hline
\end{tabular}

informal), available support, ventilatory support, the terminal period of care, support during bereavement, and palliative care services. The findings regarding coordination of care, parental support and bereavement care, effect of care and death upon siblings, and appropriateness of palliative care services are described.

Coordination-of-care concerns in the study centered on issues of lack of continuity and the difficulties involved in finding trained, experienced caregivers. Parents in the study had access to support groups but were more likely to attend them in the period following the diagnosis of muscular dystrophy. They attended the groups early in the disease process to learn practical information such as how to manage medical equipment. They found that later in the disease process they were too busy or worn out to attend. After the death of the child, bereavement care was a concern for these parents. They were interested in more formalized bereavement care such as working with a social worker who knew the family and had a rapport with them. A good family network was identified as supportive of the bereavement process.

These findings in the Australian study differ from those in the United States, where parents of children with Tay-Sachs and related disorders found support groups helped with the bereavement process. ${ }^{1}$ The parents of children with Tay-Sachs in this descriptive article could not rely on a family network because they often found themselves ostracized from their closest relatives, who were unable to accept the family affliction and its genetic origins.

Parents in the Parker et al. ${ }^{2}$ study also discussed the effect on the siblings of the ill child. Siblings have unique issues and sometimes express their grief by acting out in school or having other behavioral or performance difficulties. Having a support group with children in similar situations was thought to be helpful.

These parents' reluctance to acknowledge that their child was dying contributed to the low referral rate for palliative care services, with only 2 of 13 families referred. ${ }^{2}$ The parents did not think palliative care would be useful, and some thought palliative care was a blatant reminder that their child was dying, a fact they were not yet prepared to accept. A transition to palliative care is particularly difficult when the prognosis is uncertain because it is not clear when the "terminal phase" begins. A survey of physicians caring for patients with cystic fibrosis (CF) in Canada by Mitchell and colleagues ${ }^{13}$ demonstrates this problem. For the 45 individuals with CF who died in 1996, 25\% of the physicians never discussed palliative care and another $40 \%$ waited until the last month of the person's life to discuss palliation. In fact, the majority of the physicians' patients $(82.2 \%)$ died in the hospital, with some receiving various aggressive therapies such as mechanical ventilatory support. ${ }^{13}$

To help in identifying when a transition to palliative care is appropriate, Tonelli ${ }^{6}$ discusses different models of end-of-life care. Although the particular emphasis in his article is on people with CF, the concepts have wide application for individuals with a variety of genetic diseases. One existing model is "comfort-care only" derived from oncology. With this model, a dying patient receives only those interventions necessary to maintain comfort, usually translated to mean treatment of pain, dyspnea, and anxiety. This model may not apply to patients with CF who are at the end of life because they typically also receive other interventions such as vitamins, chest physiotherapy, antibiotics, and blood draws in the final hours of life. 
Another model is referred to by Robinson and colleagues ${ }^{14}$ as the "fusion model." This model "fuses" preventive, therapeutic, and palliative care using only interventions with a low morbidity. However, with patients with CF, some of these interventions such as chest physiotherapy and blood draws can be painful and inconsistent with a palliative approach to care.

Tonelli ${ }^{6}$ advocates using a "transitional model" of end-oflife care. With this model, decisions regarding care evolve over time and require continual reassessment regarding aggressive treatments. Consideration is given to when therapies are unlikely to return a patient to a previous baseline or when they may interfere with an acceptable quality of life. Thus the transitional model of end-of-life care recognizes the uncertainty of the prognosis (Fig. 1).

The transitional model allows for a period of time when care is neither comfort-only nor maximal. This approach to care can be difficult for health care providers who are used to an all-or-nothing approach to care. By acknowledging the transition period between full care and comfort-care only, patients, families, and caregivers may find it easier to deal with limits to treatments, do not resuscitate (DNR) orders, plans for terminal care, and farewells. One of the key aspects of the transitional model proposed by Tonelli6 is that individualized decision-making is integral to the provision of appropriate end-oflife care. With this model patients are encouraged, to the extent that they are capable, to plan and make decisions for end-oflife care. Advance care planning can help prepare individuals and their families and caregivers for the types of decisions that must be faced near the end of life.

The availability of lung transplant has added a layer of complexity to end-of-life decisions in people with CF. A case study described by Christian and colleagues ${ }^{10}$ provides a detailed perspective of the balancing act between lung transplant and quality of life in the struggle of a 21-year-old white male college student. The patient sought to put off the decision regarding lung transplant as long as possible, knowing that if he waited too long he might not be in optimal physical condition and could miss the window of opportunity to get the transplant.

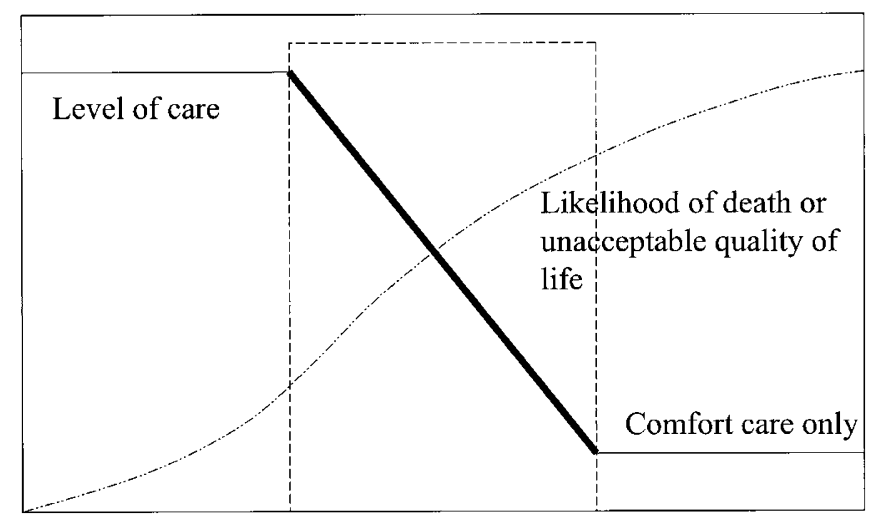

Fig. 1 The heavy line represents the often-difficult transition in level of care as prognosis worsens. Uncertainty in short-term prognosis may not allow for complete transition to comfort-care only in all patients. Reprinted from Current Opinion in Pulmonary Medicine with permission from Elsevier Science. ${ }^{6}$
In another case, Ferrin and colleagues ${ }^{11}$ discuss a 32 -yearold male patient with CF who valued his independence and was faced with a serious decline in function over a few months. The authors detail the experience of end-of-life issues from the patient's perspective: his fears of pain, death, and failing the transplant team if he died prior to transplantation. Like Tonelli, ${ }^{6}$ the authors advocate for palliative care while providing treatment, or in this case while awaiting lung transplant. They argue that the goals are consistent with each other because patients do die while awaiting transplantation.

These cases highlight that palliative care includes viewing the patient as a whole being, rather than either a transplantation candidate or a dying patient. With palliative care, clinicians provide symptom management and help the patient plan for various outcomes, including death. Ferrin and colleagues ${ }^{11}$ write, "Palliative care is quickly becoming recognized as a component of comprehensive care of patients with chronic, lifethreatening, life-limiting illnesses. It should become dominant in the care of advanced lung disease when curative interventions are ineffective and relief from physical or psychological suffering becomes the focus of care." Cases such as these also illustrate the important roles formal and informal caregivers play.

A final aspect of palliative care with genetic diseases is the real possibility that families may face the death of more than one family member because of autosomal recessive diseases or similar hereditary diseases, such as Zellweger syndrome. These families may have faced the death of their first child without the aid of palliative support and may be facing the death of a second child. In this situation, hospice can help families resolve grief from the first death and anticipate the grief process prior to the death of the second child. Hospice can also help the family achieve greater control over issues such as where the child dies, how much care the child receives, who will provide care, and, very importantly, what type of environment will be created for the remainder of the child's life.

\section{USE OF TECHNOLOGICAL INTERVENTIONS}

Technological advances have prolonged life for many people with genetic diseases, but they have also complicated decisionmaking regarding end-of-life care. For example, without technological intervention, patients with Werdnig-Hoffmann disease often die of complications of spinal muscular atrophy by the age of 2 years. In Western countries, withholding and withdrawal of life-sustaining support in patients with WerdnigHoffmann disease is standard practice. Doctors in Japan, however, provide ventilator care for these patients, who would otherwise die. Sakakihara and colleagues ${ }^{8}$ attribute the use of ventilator support in this patient population in Japan to a secure national insurance plan, general pro-life beliefs among Japanese physicians, and the families' strong wishes to prolong the lives of young people. Some would argue that the guidelines that define the futility of treatment would limit ventilator support, not only in Werdnig-Hoffmann disease, but also in other diseases in which disability and death occur early in life, 
such as muscular dystrophy. One big difference between these two groups of patients is that persons with muscular dystrophy are usually able to express their desire for treatment, so the ethical principle of patient autonomy can be supported. In contrast, patients with Werdnig-Hoffmann are usually unable to express their will. Guidelines are needed for supporting ethical decision-making regarding use of technological interventions in people with genetic diseases who are at the end of their lives.

Another technological intervention that is used more often now is nonintubated forms of assisted ventilation. Such interventions can influence end-of-life care in persons with CF, especially for those awaiting lung transplantation. Persons with different forms of muscular dystrophy are also using long-term home mechanical ventilation, which is changing the care of these patients.

Using a ventilator to extend life in the muscular dystrophy population is controversial. It is necessary to assess the prognosis for pulmonary and cardiac sequelae when planning longterm therapy in this population. Patients with Duchenne muscular dystrophy (DMD) and severe cardiomyopathy are not considered to be good candidates for long-term assisted ventilation, nor are they considered to be good candidates for heart transplant owing to the severity of the skeletal muscle disease and its unrelenting progression. Persons with other forms of muscular dystrophy such as Becker muscular dystrophy are considered to be better choices for transplant because of their greater functional status and greater life expectancy.

Between 1984 and 1993 Hilton and colleagues ${ }^{5}$ at the Loma Linda Medical Center managed 14 patients with DMD on long-term mechanical ventilation. The authors found that the quality of life of these patients improved when discharge planning was initiated, and they had the hope of returning home. Of concern to the Loma Linda team was that decisions regarding long-term ventilation were made during an episode of acute respiratory failure. To prevent such important decisions from being made under these stressful circumstances, the team developed an algorithm (Fig. 2) to facilitate long-term decisions regarding ventilation. If the patients and families choose not to use mechanical ventilation, they are referred to hospice. If mechanical ventilation is chosen, the patients are admitted to the hospital to initiate therapy. Once the patients are stabilized on ventilation, they are discharged either to home on home mechanical ventilation or to a subacute care facility.

Technological progress emphasizes the need for advance care planning and directives. Advance care planning for persons with progressive genetic disorders should ideally be done when the person is not acutely ill, rather than in an emergency situation. For families of young children who are unable to decide for themselves, a discussion early in the course of the disease is appropriate. Having these discussions may not occur spontaneously because patients in general do not initiate these discussions with their physicians even though they desire to have such discussions. ${ }^{15,16}$ This finding emphasizes the importance of health care providers' initiating these discussions.

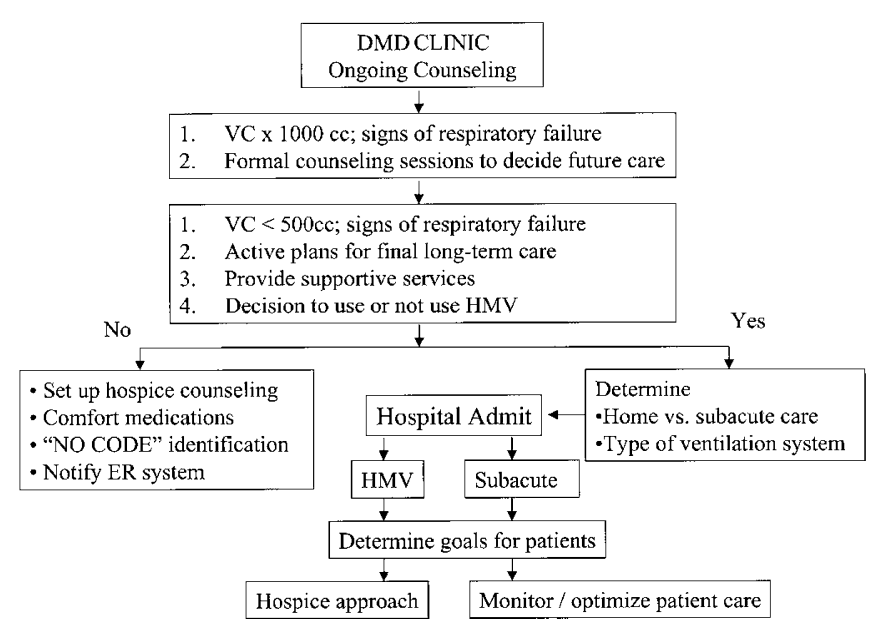

Fig. 2 This algorithm delineates an approach to the end-of-life care for patients with DMD. Once early respiratory failure becomes evident, more intensive evaluation and counseling are indicated. Establishment of advanced directives concerning issues related to emergency and intensive care including resuscitation, intubation, and placement on mechanical ventilation as well as choices regarding long-term management need to be considered. VC, vital capacity; HMV, home mechanical ventilation; ER, emergency response. Reprinted from Pediatric Neurology, copyright 1993, with permission from Elsevier Science. ${ }^{5}$

\section{ETHICAL DECISIONS}

In confronting ethical decisions in health care, there are many considerations such as the medical indications for and the effectiveness of therapies, the patient's preferences, quality of life, contextual features, and cost/benefit questions. The medical indications include knowing the patient's current medical condition and prognosis with and without further intervention, and which options are technologically feasible and physiologically possible. It is necessary for clinicians to present this information factually and without bias to the patient. The clinicians' training and experience, necessarily, influence the manner in which options are presented.

In the past, physicians were often reluctant to involve patients in decision-making, but the movement toward selfdetermination has gained prominence. ${ }^{5}$ For example, physicians hesitated to begin therapy that had only a small chance of succeeding because they did not want to withdraw that therapy should it fail. It is now recognized that "no moral or legal difference exists between withholding and withdrawing treatment." ${ }^{17}$ So the current thinking is that it is worth trying an intervention and, if it does not meet the patient's goals, withdrawing it. In Western cultures, value is placed on patients making their own decisions; thus patients from these backgrounds should be involved in discussions and decisions regarding treatment options at whatever level they are willing and able to participate.

As with the decisions regarding home ventilation in patients with DMD, quality of life is a crucial component of end-of-life decision-making. It is interesting, however, that health care providers and family members tend to view quality of life differently from patients. Health care providers and family members measure a patient's quality of life in terms of the physical dimension, while the patient more often measures quality of 
life in social and cognitive terms. ${ }^{5}$ These differences emphasize that caregivers and family members may not be fully aware of the patient's wishes or values. When considering using different therapies in genetic disorders, health care providers need to consider that quality of life is deeply subjective and personal, and contextual factors such as the effect on family members enter into the assessment of quality of life.

In situations in which a person's judgments of quality of life cannot be known, such as with neonates who have genetic diseases, information such as factual medical data or traditional ethical and moral principles must be used. In this type of situation, the hospital ethics committee might choose to consider the rights and best interests not only of the patient and family, but also the community of caregivers. Consideration might include issues such as the difficulty in assessing levels of pain in the neonate, limitations of ethical theory with regard to critical care, and the importance of including caregivers' needs in the ethical decision-making process. Dagi ${ }^{12}$ believes in the process of formal ethical discourse, but he takes issue with the idea of consensus in ethical decision-making because the emotional needs of the child, family, and caregivers may conflict. He concludes that it is essential not to confound the technical problem of assessing pain and suffering with the ethical issue of judgments about pain and suffering.

\section{ISSUES FACING CAREGIVERS AND THE COMMUNITY}

When assessing end-of-life issues in genetic disorders, concerns regarding the family and community arise. Labbe ${ }^{9} \mathrm{com}-$ pared the perceptions of family functioning and the emotional states of 32 primary caregivers of children with Batten disease (cerebral sphingolipidosis) with those of 11 primary caregivers of children with chronic and less severe medical disorders. She found that the group with Batten disease reported significantly higher scores on depression and anxiety measures and a greater negative impact on their health and schedule and had less perceived family cohesion than the control group. She concluded that caregivers of children with terminal genetic diseases may be at greater risk for emotional and family difficulties, and referral for psychological interventions for depression and family therapy may be helpful for these caregivers.

Livneh and colleagues ${ }^{7}$ studied the psychosocial reactions of families who had a child with progeria. As the child's disease progressed, family members reported feeling its impact physically, emotionally, spiritually, and cognitively. Sibling grief at the death of the child is great and is compounded by feelings of confusion, anxiety, betrayal, and emptiness. These authors go on to outline psychosocial intervention strategies that are extrapolated from the literature.

For the child dying of progeria, Livneh and colleagues ${ }^{7}$ recommend not lying or being overprotective, answering his or her questions, and providing education about the various treatments, medical management issues, and course of the disorder. For the siblings, the authors generally advocate encouraging them to participate in the illness and dying experience, giving them emotional support, addressing guilt feelings, and assuring them that progeria is not contagious. For the family unit, efforts at communication among family members should be made and there should be an opportunity to express feelings of anxiety, guilt, and depression. Family members should regularly visit the child at home and during hospital stays and should focus on the positive aspects of the years the child has lived. Parents and siblings may benefit from peer support groups, and finances should be reviewed.

Mack and Berman ${ }^{1}$ describe a support group for parents of children with progressive genetic disorders. The mother of a child who died of Tay-Sachs disease formed this group in 1984, and the group has continued. One of the unique features of this group is that parents may continue in the group even after their child dies. Groups such as this face a big challenge because members include parents of children who are at different stages of the disease and of life itself. The group can provide mutual aid and information-sharing, which helps parents feel less helpless and more adequate. Parents of children with genetic disorders may experience ostracism from their families, who do not want to acknowledge that this disease could have happened to them. The families, who feel abandoned after their child dies, receive an "ongoing sense of security and support" from the group. ${ }^{1}$

A child's progressive disease can have an impact on the school community, as described in the case report of a 7-yearold boy with adrenal leukodystrophy. ${ }^{3}$ The boy's terminal status was acknowledged with a DNR request, but despite his tenuous condition, the boy and his parents wanted him to continue in school as long as possible. Ethically, it would have violated the child's autonomy not to honor his wish for no resuscitation, but the DNR status presented legal issues for the school. The parents and the school worked together to reduce the potential for legal liability, and they addressed the potential harm to the other students. Consequently, the schoolmates went through the dying process with the child as he changed from an active first grader into a boy who could not even speak in second grade. His deterioration was rapid, and the school went through hospice with him. The school staff made a courageous and rewarding choice by remaining connected to the family unit throughout the child's terminal stage, allowing the experience to become an opportunity for learning and growth. The children worked with a social worker and the school nurse, and the hospice team acted as consultants to the school when needed. Ramer-Chrastek ${ }^{3}$ writes that societal change in our attitudes regarding death and dying will hopefully come so that death can be seen as a natural part of life instead of something to be ashamed of and fear. As insurance companies encourage dying at home to contain costs, death may once again become part of common experience.

\section{CONCLUSIONS}

The literature on end-of-life issues in people with genetic disorders is sparse. Some of the more common genetic disorders that exhibit very high mortality rates, such as trisomy 13 and 18, were not addressed in the end-of-life literature. As our 
understanding of genetic disorders expands, we will need also to expand our understanding of the issues of palliative care, ethical decision-making, use of technological interventions, and the impact of the decisions and technologies on families and the community. There is no defined model for end-of-life care in genetic disorders. Even in CF, which is better described than other genetic disorders, clinicians and researchers are still attempting to refine approaches to care. This review of literature provides a starting point from which to propose recommendations for future research on end-of-life care for people with genetic disorders.

\section{References}

1. Mack SA, Berman LC. A group for parents of children with fatal genetic illnesses. Am J Orthopsychiatry 1988;58:397-404.

2. Parker D, Maddocks I, Stern LM. The role of palliative care in advanced muscular dystrophy and spinal muscular atrophy. J Paediatr Child Health 1999;35:245-250.

3. Ramer-Chrastek J. Hospice care for a terminally ill child in the school setting. J Sch Nurs 2000;16:52-56.

4. Wolfe J. Hospice support for families facing multiple deaths of children. Am J Hosp Palliat Care 1997;14:224-227.
5. Hilton T, Orr R, Perkin R, Ashwal S. End of life care in Duchenne muscular dystrophy. Pediatr Neurol 1993;9:165-177.

6. Tonelli MR. End-of-life care in cystic fibrosis. Curr Opin Pulm Med 1998;4:332-336.

7. Livneh H, Antonak R, Maron S. Progeria: medical aspects, psychological perspectives, and intervention guidelines. Death Stud 1995;19:433-452.

8. Sakakihara Y, Masaya K, Kim S, Oka A. Long-term ventilator support in patients with Werdnig-Hoffmann disease. Pediatr Int 2000;42:359-363.

9. Labbe E. Emotional states and perceived family functioning of caregivers of chronically ill children. Psychol Rep 1996;79:1233-1234.

10. Christian BJ, D'Auria J, Jennifer P, Moore CB. Playing for time: adolescent perspectives of lung transplantation for cystic fibrosis. J Pediatr Health Care 1999;13:120125.

11. Ferrin M, Happ MB, Kagan SH. Palliative care and lung transplantation: conflict or continuum? Nursing Rounds at the University of Pennsylvania 2001;101:61-66.

12. Dagi TF. Compassion, consensus and conflict: should caregivers' needs influence the ethical dialectic? J Clin Ethics 1992;3:214-218.

13. Mitchell I, Nakielna E, Tullis E, Adair C. Cystic fibrosis: end stage care in Canada. Chest 2000;118:80-84.

14. Robinson WM, Ravilly S, Berde C, Wohl ME. End of life care in cystic fibrosis. Pediatrics 1997;100:205-209.

15. Man GCW, Hsu K, Sproule BJ. Effect of alprazolam on exercise and dyspnea in patients with chronic obstructive pulmonary disease. Chest 1986;90:832-836.

16. Young IH, Daviskas E, Keena VA. Effect of low dose nebulized morphine on exercise endurance in patients with chronic lung disease. Thorax 1989;44:387-390.

17. President's Commission for the Study of Ethical Problems in Medicine and Biomedical and Behavioral Research. Deciding to forgo life-sustaining treatment. Washington, DC: US Government Printing Office, 1983. 